\title{
EXPERIÊNCIAS EDUCATIVAS EM ESPAÇOS EDUCATIVOS NÃO FORMAIS EM UM GRUPO DE FUTUROS PROFESSORES DE CIÊNCIAS E BIOLOGIA
}

\author{
EDUCATIONAL EXPERIENCES IN NON-FORMAL EDUCATIONAL SPACES IN A \\ GROUP OF FUTURE SCIENCE AND BIOLOGY TEACHERS
}

\begin{abstract}
Ryan Araújo de Sousa ${ }^{1}$, João Gabriel Silva Silva² e Reginaldo dos Santos ${ }^{3}$
1 Universidade Federal do Pará, Faculdade de Ciências Biológicas, Campus de Altamira, Brasil, Email: ryanrock1314@gmail.com, ORCID: https://orcid.org/0000-0003-4510-3356

2 Universidade Federal do Pará, Faculdade de Ciências Biológicas, Campus de Altamira, Brasil, Email: gabrielufpa@ufpa.br, ORCID: https://orcid.org/0000-0003-0321-0612

${ }_{3}$ Universidade Federal do Pará, Faculdade de Ciências Biológicas, Campus de Altamira, Brasil, Email: reginaldosantosmira@gmail.com, ORCID: https://orcid.org/0000-0002-2282-8226
\end{abstract}

ARTICLE INFO

Article history:

Received 2020-09-25

Accepted 2020-12-12

Available online 2020-12-12
Palavras-chave: Espaço Não Formal. Experiência Educativa. Formação Docente.

Keywords: Non-Formal Space. Educational Experience. Teacher Training.

RESUMO. Considerando que saber usar estratégias metodológicas adequadas aos objetivos de ensinoaprendizagem pretendidos, saber planejar e executar planos de ensino-aprendizagem contextualizados, e se possivel interdisciplinar, representa hoje competências profissionais fundamentais para o exercício da profissão de professor, e ainda, considerando que usar espaços não formais no ensino formal pode ser uma importante possibilidade e estratégia didática para a promoção de um ensino escolar contextualizado e interdisciplinar, conforme apontaram os Parâmetros Curriculares Nacionais, na segunda metade da década de 1990, e recentemente ratificados pela Base Nacional Comum Curricular, este artigo apresenta os resultados de uma pesquisa desenvolvida em 2019, com o objetivo de conhecer e analisar experiências educativas em espaços não formais que tiveram um grupo de licenciandos em Ciências Biológicas durante $o$ período em que cursaram a Educação Básica. Como técnica e instrumento de coleta de dados, a pesquisa usou questionário com perguntas do tipo fechadas e do tipo aberta. Os resultados mostraram que esses licenciandos, na sua quase totalidade, não tiveram nenhuma oportunidade de experimentar aulas com uso desses espaços em seu processo formativo escolar no nível da Educação Básica.

ABSTRACT. Considering that knowing how to use appropriate methodologies for the intended teaching and learning objectives, knowing how to plan and execute contextualized teaching and learning plans, and if possible interdisciplinary, today represents fundamental professional skills for the exercise of the teaching profession, and also considering that using non-formal spaces in formal teaching can be an important possibility and didactic strategy for the promotion of a contextualized and interdisciplinary school teaching, as pointed out by the National Curricular Parameters in the second half of the 1990s and recently ratified by the Common National Curricular Base, this article presents the results of a research developed in 2019, with the objective of knowing and analyzing educational experiences in non-formal spaces that had a group of students in Biological Sciences during the period they attended Basic Education. As a technique and instrument of data collection, the research used a questionnaire with closed and open type questions. The results that these undergraduates, in their almost totality, did not have any opportunity to experiment with classes using these spaces in their school formative process at the level of Basic Education. 


\section{Introdução}

O processo de democratização da educação escolar trazido com a aprovação da atual Constituição Federal (CF), em 1988, recai sobre a escola e seus professores o grande desafio de pensar e implementar métodos de atuação pedagógica, coerentes com as atuais e diferentes necessidades educacionais de todas as pessoas que da escola têm o mesmo direito.

O marco legal desse direito a todos e desafio aos professores está expresso no Art. 205 dessa CF, onde se diz que "A Educação, direito de todos e dever do Estado e da família, será promovida e incentivada com a colaboração da sociedade, visando ao pleno desenvolvimento da pessoa, seu preparo para o exercício da cidadania e sua qualificação para o trabalho" (BRASIL, 1988, p. 69).

Frente a esse dever que recai sobre a escola, podemos considerar que, na atualidade, uma das principais competências docente é a capacidade de domínio amplo e profundo sobre métodos de ensino para uma educação inclusiva e de boa qualidade (BRASIL, 1998, 1999; 2017; IMBERNÓN, 2010).

Quando se fala em método de ensino, fala-se de um modo de se fazer o ensino formal, que por sua vez, se caracteriza pela intencionalidade - os sujeitos envolvidos desejam que a ação educativa aconteça -, pela institucionalidade - a ação educativa irá acontecer em uma instituição credenciada própria para isso -, e pela sistematização - a ação educativa segue um currículo oficial (LIBÂNEO, 2010).

As ideias sobre o que tomamos por método de ensino escolar, são e sempre foram influenciadas pelas pesquisas de diferentes áreas de conhecimento - a Psicologia, a Sociologia entre outras - e pelo contexto social, político, histórico, econômico, científico, tecnológico e cultural (DELIZOICOV; ANGOTTI; PERNAMBUCO, 2011). No entanto, todas essas influências aludem a ideia de método de ensino como uma ação que envolve o uso de recursos - materiais, físicos, financeiros, humanos... -, mediante técnicas e estratégias fundamentadas em concepções teóricas, metodológicas e epistemológicas (KRASILCHIK, 2011; LIBÂNEO, 2013).

Por influência do ensino tradicional ancorado na ideia de mundo dual de Platão e no Behaviorismo, por muito tempo, acreditou-se que ensino e a aprendizagem escolar poderiam ser praticados e desenvolvidos, respectivamente, sem considerar as influências dos espaços não escolares. Hoje, por influencia das teorias cognitivistas e o construtivismo, acredita-se que a aprendizagem escolar é significativamente influenciada pelos diferentes meios - físico, social, histórico, cultural, econômico..., nos quais o sujeito cognoscente se insere de forma intencional ou não intencional (BRASIL, 1998; OLIVEIRA, 2000; PORTILHO, 2009). 
Considerando que ensino, aprendizagem e educação são processos que ocorrem em todos os âmbitos da vida humana, então uma maneira de entendermos de forma mais detalhada esses processos é classificar o ensino, a aprendizagem e a educação em: formal, não formal e informal. $E$ daí, considerar também como formal, não formal e informal, os espaços nos quais esses processos ocorrem (LIBÂNEO, 2010).

Vale salientar que, assim como discorre Marandino (2017), não é simples, e talvez nem seja possível classificar, literalmente, ensino, aprendizagem, educação e os espaços em formal, não formal e informal, pois sempre haverá uma situação em que há sobreposição desses processos e espaços. Pois, o processo educacional, seja ele formal, informal ou não formal, não ocorre de forma estanque no e sobre o sujeito cognoscente.

Segundo Libâneo (2010), podemos tomar como espaços formais aqueles destinados a promover o ensino e a aprendizagem de forma intencional, institucionalizada e sistematizada, e a escola é um dos exemplos desses espaços. Neles há elementos que foram pensados segundo uma legislação e uma normatização nacional ancorada em concepções metodológicas, teóricas e epistemológicas sobre ensino, aprendizagem e educação.

Assim como discorrem Jacobucci (2008) e Pina (2014), outros ambientes considerados não escolares também podem contribuir com a aprendizagem escolar porque lá também ocorre ou pode ocorrer ensino, aprendizagem e educação intencional e/ou não intencional, e assim, são considerados como ambientes de grande potencial de contribuição para o ensino formal. Esses espaços são também denominados por espaços não formais. Zoológico, museus, uma floresta, estação de tratamento de água e esgoto, uma plantação agrícola são alguns dos muitos exemplos desses espaços, (MARTINS, 2009; MARQUE; FREITAS, 2017).

Com as publicações dos Parâmetros Curriculares Nacionais (PCN) para as últimas séries do Ensino Fundamental, a partir de 1998, o sistema de ensino brasileiro passa a sugerir que os professores, desde os primeiros anos do Ensino Fundamental, usem diferentes espaços não escolares, para assim proporcionar aos educandos um ensinoaprendizagem mais contextualizado, atrativo e interdisciplinar, possibilitando oportunidades para o educando ser mais protagonista sobre sua própria aprendizagem e formação escolar.

A ideia posta pelos PCN, e agora ratificada pela Base Nacional Comum Curricular, em Brasil (2017), é que o educando perceba que não há ou que pelo menos não deve haver separação entre o mundo da vida escolar e o mundo da vida não escolar. Ou seja, um bom ensino-aprendizagem escolar é aquele que, entre outras coisas, permite que o educando perceba naturalmente que os assuntos escolares também fazem parte do seu cotidiano e vice-versa.

E essa ideia de não separação entre a escola e a vida do sujeito cognoscente não é recente. Assim como discorre Cunha (1994), o filósofo John Dewey (1859-1952), já dizia 
que não pode haver separação entre a escola e a vida do educando, porque a escola não é somente a preparação estanque e propedêutica para a vida futura, a escola já é a própria vida do educando.

Essa concepção epistemológica está incorporada pela legislação educacional brasileira no Artigo $1^{\circ}$ da atual Lei de Diretrizes e Bases da Educação Nacional (LDB), onde se diz que:

A educação abrange os processos formativos que se desenvolve na vida familiar, na convivência humana, no trabalho, nas instituições de ensino e pesquisa, nos movimentos sociais e organizações da sociedade civil e nas manifestações culturais. $\S 1^{0}$ Esta lei disciplina a educação escolar, que se desenvolve, predominantemente, por meio do ensino, em instituições próprias. $\S 2^{\circ} \mathrm{A}$ educação escolar deverá vincular-se ao mundo do trabalho e à prática social (BRASIL, 1996, p. 1).

Frente ao que foi apresentado, este artigo apresenta os resultados de uma pesquisa desenvolvida no segundo semestre de 2019, com o objetivo de conhecer e analisar experiências educativas em espaços não formais que tiveram um grupo de licenciandos em Ciências Biológicas, durante o período em que cursaram a Educação Básica.

\section{Desenvolvimento}

\subsection{Metodologia}

Esta pesquisa é classificada como pesquisa qualitativa, em relação a sua abordagem, pesquisa exploratória, em relação ao seu objetivo e pesquisa de levantamento, em relação aos seus procedimentos (LAVILLE; DIONNE, 1999; GERHARDT; SILVEIRA, 2009; MASSONI, MOREIRA, 2016), e como técnica e instrumento de coleta de dados, os pesquisadores usaram o seguinte questionário estruturado, conforme mostra o Quadro 1, exposto a seguir.

\section{Quadro 1 - Questionário da pesquisa}

\section{Pesquisa sobre Experiência Educativa em Espaços Educativos Não Formais}

Parte A - Identificação:

1. Sexo: masculino ( ); feminino ( ).

2. Idade: anos.

3. Está cursando qual ano do curso?

Parte B - Experiência Educativa:

1. Você já ouviu falar em espaços não formais de ensino, aprendizagem e educação?

a)( ) não.

b)( ) sim. 
2. Você sabe dizer o que são esses espaços?

a)( ) não.

b)( ) sim.

3. Você teve alguma aula fora do espaço escolar durante o tempo que estudou a Educação Básica?

a)( ) não.

b)( ) sim. Se sim, diga o nome do local onde essa aula aconteceu, qual foi o objetivo dessa aula e quais assuntos lá foram tratados.

Fonte: Elaborado pelos autores

Este questionário foi aplicado a um grupo composto por 38 discentes de um curso de Licenciatura em Ciências Biológicas de uma universidade federal do Norte do país, sendo $52 \%$ do sexo masculino e $48 \%$ do sexo feminino, com faixa etária entre 18 a 47 anos, conforme mostra o Quadro 2, exposto a seguir, e que se encontravam cursando os dois primeiros anos dos quatro anos do curso. O critério para o discente ser incluído na pesquisa foi apenas aceitar dela participar no momento em que os pesquisadores a eles fizeram o convite.

Quadro 2 - Faixa etária dos sujeitos da pesquisa

\begin{tabular}{|c|c|c|c|c|}
\hline Faixa Etária & De 18 a 22 anos & De 23 a 27 anos & De 28 a 32 anos & De 36 a 47 anos \\
\hline Número & 30 & 4 & 3 & 1 \\
\hline
\end{tabular}

Fonte: Elaboração pelos autores

\subsection{Resultados e Discussão}

Com este arranjo metodológico a pesquisa obteve os seguintes resultados: Ao serem indagados se já haviam ouvido falar em espaços não formais de ensino aprendizagem e educação, $83 \%$ respondeu que sim e 17\% respondeu que não, conforme mostra a Tabela 1 , exposta a seguir.

Tabela 1 - Respostas para a primeira pergunta

\begin{tabular}{c|c}
\hline Alternativas de respostas para a primeira pergunta & Percentuais de respostas \\
\hline Sim & $83 \%$ \\
\hline Não & $17 \%$ \\
\hline
\end{tabular}

Fonte: Elaborado pelos autores

Ao serem indagados se sabiam dizer o que são espaços não formais, $73 \%$ responderam que sim e $27 \%$ respondeu que não sabia, conforme mostra a Tabela 2 , exposta a seguir. 
Tabela 2 - Respostas para a segunda pergunta

\begin{tabular}{c|c}
\hline Alternativas de respostas para a segunda pergunta & Percentuais de respostas \\
\hline Sim & $73 \%$ \\
\hline Não & $27 \%$ \\
\hline
\end{tabular}

Fonte: Elaborado pelos autores

Do mesmo modo, ao serem indagados se tiveram alguma oportunidade de ter experimentado alguma aula fora do espaço escolar tradicional, $42 \%$ respondeu que sim e a maioria, 58\%, respondeu que não, conforme mostra a Tabela 3, exposta a seguir.

Tabela 3 - Respostas para a terceira pergunta

\begin{tabular}{c|c}
\hline Alternativas de respostas para a segunda pergunta & Percentuais de respostas \\
\hline Não & $58 \%$ \\
\hline Sim & $42 \%$ \\
\hline
\end{tabular}

Fonte: Elaborado pelos autores

Ao responder sim para a terceira questão, estes $42 \%$, ou seja, 16 discentes citaram os seguintes locais que visitaram quando estavam cursando a Educação Básica, e que eles consideram como sendo espaços não formais, conforme mostra o Quadro 3, exposto a seguir.

Quadro 3 - Espaços não formais citados pelos sujeitos da pesquisa

\begin{tabular}{|l|c|c|}
\hline \multicolumn{1}{|c|}{ Espaço } & № de citação & \multirow{2}{*}{ Total } \\
\hline Orla do Cais de Altamira-PA & 3 & \multirow{2}{*}{8} \\
\hline Eletronorte & 1 & \\
\hline Balneário Recanto Cardoso & 1 & \\
\hline Quartel da Polícia Militar & 1 & \multirow{2}{*}{6} \\
\hline Barracão Comunitário & 1 & \\
\hline Praça pública & 1 & \\
\hline O Pátrio da escola & 3 & 2 \\
\hline A quadra da escola & 2 & \\
\hline A cozinha da escola & 1 & \\
\hline A horta da escola & 2 & \\
\hline
\end{tabular}

Fonte: Elaborado pelos autores

Como se pode perceber, metade dos discentes que afirma ter vivenciado experiência de aula fora do espaço escolar, na verdade, não tiveram essa experiência, pois o que citaram são espaços do próprio ambiente escolar (pátio, quadra e cozinha da escola), e até uma estratégia metodológica - a produção da horta escolar - como sendo uma experiência educacional fora do espaço tradicional de ensino. 
Conforme aqui foi anteriormente discutido com base em em Jacobucci (2008) Martins (2009), Libâneo (2010) e Pina (2014), o pátio da escola não é um espaço não formal, pois ele pertence à escola, um espaço formal. Assim como discorrem Marque e Freitas (2017), quando diferentes locais da escola são citados como espaços não formais, isso, provavelmente, tem a ver com o entendimento equivocado que espaços não formais são apenas locais fora da sala de aula. Além disso, essa percepção, provavelmente, tem a ver também com a tradição em se pensar estratégias didáticas e perceber apenas a sala de aula e a escola como possibilidades de recursos didáticos para o ensino-aprendizagem escolar.

Diante dessas citações e de todas as respostas dos 38 discentes, é possível perceber que em sua quase totalidade, $82 \%$ desses discentes passaram pela Educação Básica sem ter experimentado outros ambientes de aula formal, se não o ambiente escolar tradicional.

Considerando que já se passaram 23 anos do lançamento dos PCN, e considerando que a maioria desses discentes tem idade que nos indica que esses cursaram a Educação Básica mediante currículos que deveriam seguir as orientações desses documentos oficiais (os PCN), então, podemos concluir que esses discentes, em sua quase totalidade, estudaram em escolas que, por alguma razão, não consideraram as orientações dos PCN no que diz respeito ao uso dos espaços não escolares como possibilidades para o professor diversificar suas estratégias de ensino-aprendizagem escolar, tendo em vista um ensino mais atrativo para os educandos e, talvez, até mais contextualizado.

Outro aspecto que muito chamou a atenção no estudo das respostas desses discentes (os que disseram ter experimentado aulas em ambientes fora do espaço escolar) diz respeito ao planejamento dessas aulas. Somente os três discentes que citou o Cais do Porto de Altamira, explicaram que foram até o local para uma aula de Educação Ambiental, e lá discutiram a relação do homem com a natureza em um espaço em que há diferentes elementos naturais e elementos construídos pelo homem para serem usados para o lazer e entretenimento do público em geral.

Ao citar a Eletronorte - uma empresa de geração de energia hidroelétrica -, o discente informou que ao visitar o local com sua turma de estudo, os monitores fizeram explicações sobre espécies de peixes da região e sobre a importância da preservação desses, no entanto, o discente afirmou que a aula aconteceu muito mais como uma espécie de passeio para conhecer a usina de geração de energia hidroelétrica, do que como uma aula para estudar de forma contextualizada um determinado conteúdo ou tema de estudo escolar.

Do mesmo modo, ao citar o Balneário Recanto Cardoso como um espaço não formal, foi dito que lá foram trabalhados assuntos relacionados à disciplina escolar 
Geografia, porém, o discente não especificou qual tema dessa disciplina foi trabalhado, como foi trabalhado e nem por que eles realizaram a visita ao local.

O Quartel da Polícia foi citado por uma pessoa, o Barracão Comunitário e a Praça também foram citados por uma pessoa, respectivamente, porém, em nenhuma dessas três citações esses discentes informaram o que nesses locais receberam como ação educativa de ensino-aprendizagem e educação escolar.

Com base nestas respostas, percebe-se que esses discentes tiveram pouco contato com os espaços não formais de ensino, aprendizagem e educação, e os que tiveram, possivelmente, não experimentaram uma aula bem planejada, com objetivos claros sobre quais seriam as aprendizagens que deveriam ser desenvolvidas ao visitarem esses locais.

Trabalhos como o de Fonseca e Viana (2017) que pesquisaram sobre as possibilidades de uso das estações de tratamento de água e esgoto como importantes possibilidades para a promoção de um ensino escolar mais contextualizado, e o trabalho de Junior-Trindade, Amaral e Malheiro (2014) que discorrem sobre a necessidade de uso de espaços não formais no ensino formal para ampliar o interesse dos jovens pelo ensinoaprendizagem escolar, são enfáticos ao afirmar que uma aula ou um projeto de estudo com uso de espaço não formal, sem planejamento adequado, pode atuar muito mais como obstáculo para a escola do que como contributo para a melhoria da sua atuação enquanto instituição de ensino intencional, sistematizado e institucionalizado. Em outras palavras, quando o educando não compreende aquilo que fez e por que fez, ele, provavelmente, não irá valorizar essa ação educativa e formativa.

Assim como discorre Vasconcelos (2014), qualquer aula sem planejamento claro para os alunos e para o professor, está mais vulnerável a cair no esquecimento ou se transformar em uma experiência vaga na cabeça dos alunos como sendo apenas um passeio para quebra de rotina escolar. $E$ isso, provavelmente, empobrece a função social da escola. Assim, conforme discorre Libâneo (2010), é no planejamento bem elaborado que o ensino escolar se caracteriza efetivamente como ensino intencional, institucionalizado e sistematizado de boa qualidade.

Ainda segundo Libâneo (2010) e Vasconcelos (2014), é no planejamento que o professor deve pensar sobre a oportunidade que aquela aula, em um espaço não formal, irá possibilitar à promoção de um estudo escolar mais contextualizado, em que o educando percebe as interações e interdependências entre o mundo escolar e o não escolar.

Não que a escola não deva promover passeios e momentos de entretenimento com os alunos, o que não é aconselhado se não houver planejamento ou planejamento claro para os discentes compreenderam os rumos que a escola imprime em suas aprendizagens, afinal de contas, conforme orientam os PCN e, mais recentemente, a Base Nacional Comum Curricular, em Brasil (2017; 2018), em um ensino escolar que tem por finalidade o pleno 
desenvolvimento da pessoa, seu preparo para o exercício da cidadania e a sua qualificação para o trabalho, conforme está no Artigo 205 da CF e no Artigo 2 da atual LDB, o aluno deve ser o protagonista da sua aprendizagem escolar, e o professor precisa esforçar-se para que isso, de fato, ocorra em suas aulas. Eis o desafio.

\section{Considerações Finais}

Frente aos resultados aqui apresentados, a pesquisa foi concluída considerando que o contato que esses discentes tiveram com esses espaços educacionais não formais de ensino, aprendizagem e educação, foi significativamente reduzido e superficial, não passando de um simples passeio, conforme tradicionalmente os espaços não formais foram e ainda são usados e percebidos pela maioria das escolas de Educação Básica e seus professores.

Considerando que esses discentes são futuros professores da Educação Básica, entende-se que essa defasagem precisa ser sanada para que estes, quando estiverem atuando como professores, possam ter uma visão mais alargada sobre as potencialidades, possibilidades e vantagens do uso dos espaços não formais como um contributo para o ensino formal.

\section{REFERÊNCIAS}

BRASIL. Presidência da República. Casa Civil. Subchefia para Assuntos Jurídicos. Constituição da República Federativa do Brasil de 1988. Diário Oficial [da União], Brasília, DF, 05 out. 1988. Seção I, p. 1. Ministério da Educação. Lei no 9.394, de 20 de dez. de 1996. Lei de Diretrizes e

Bases da Educação Nacional. Estabelece as diretrizes e base da educação nacional. Diário Oficial [da União], Brasília, DF, 23 dez. 1996. Seção I, p. 27.833.

Ministério da Educação e do Desporto. Secretaria de Educação Fundamental. Parâmetros curriculares nacionais: terceiro e quarto ciclos do ensino fundamental: introdução aso parâmetros curriculares nacionais. Brasília: MEC/SEF, 1998.

Ministério da Educação. Secretaria de Educação Média e Tecnológica. Parâmetros curriculares nacionais. Brasília: MEC/SEMT, 1999.

Presidência da República. Casa Civil. Subchefia para Assuntos Jurídicos. Resolução CNE/CP no 8, de 22 de dezembro de 2017. Institui e orienta a implantação da Base Nacional Comum Curricular, a ser respeitada obrigatoriamente ao longo das etapas e respectivas modalidades no âmbito da Educação Básica. Diário Oficial [da União], Brasília, DF, 22 dez. 2017. Seção I, p. 41-44. 
Ministério da Educação. Resolução CNE/CP no 4, de 17 de dezembro de 2018. Institui a Base Nacional Comum Curricular na Etapa do Ensino Médio (BNCC-EM), como parte final da Educação Básica, nos termos do artigo 35 da LDB, completando o conjunto constituído pela BNCC da Educação Infantil e do Ensino Fundamental, com base na Resolução CNE/CP no 2/2017, fundamentada no Parecer CNE/CP no 15/2017. Diário Oficial [da União], Brasília, DF, 18 dez. 2018. Seção I, p. 120.

CUNHA, Marcus Vinícius. John Dewey: uma filosofia para educadores em sala de aula. 3. ed. Petrópolis: Vozes, 1994.

DELIZOICOV, Delizoicov; ANGOTT, José André; PERNAMBUCO, Marta Maria. Ensino de Ciências: fundamentos e métodos. 4. Ed. São Paulo: Cortez, 2011.

FONSECA, Priscila Stefany Pontes da.; VIANA, Rafaelle Nazário. A utilização de um espaço não formal como recurso estratégico para o Ensino de Ciências. SOUTH AMERICAN Journal of Basica Education, Technical and Technological, v. 1, n. 1, p. 335-344, 2017. Disponível em: <https://periodicos.ufac.br/index.php/SAJEBTT/article/view/1292>. Acesso em: 25 jan. 2020.

GERHARDT, Tatiana Engel; SILVEIRA, Denise Tolfo (Orgs.). Método de pesquisa. Porto Alegre: Editora da UFRGS, 2009.

IMBERNÓN, Francisco. Formação docente e profissional: formar-se para a mudança e a incerteza. Tradução Silvana Cobucci Leite. 8. ed. São Paulo: Cortez, 2010.

JACOBUCCI, Daniela Franco Carvalho. Contribuições dos espaços não formais de educação para a formação da cultura científica. EM EXTENSÃO, v. 7, 2008. Disponível em: <http://www.seer.ufu.br/index.php/revextensao/article/view/20390/10860>. Acesso em: 24 jan. 2020.

JUNIOR-TRINDADE, Saint-Clair Cordeiro; AMARAL, Marcio Douglas Brito; MALHEIRO, Bruno Cezar Pereira. Praticando a geografia em ambientes não-escolares: uma experiência na orla fluvial de Belém-Pará. Ensino, Geografia e Pesquisa, v. 18, n. 1, p. 85-98, 2014. Disponível em: <https://periodicos.ufsm.br/geografia/article/view/7481>. Acesso em: 14 jan. 2020.

KRASILCHIK, Myriam. Prática de ensino de biologia. 4. ed. São Paulo: Editora da Universidade de São Paulo, 2011.

LAVILLE, Christian; DIONNE, Jean. A construção do saber: manual de metodologia da pesquisa em Ciências Humanas. Tradução Heloísa Monteira e Francisco Settineri. Porto Alegre: Artimed; Belo Horizonte: Editora UFMG, 1999.

LIBÂNEO, José Carlos. Pedagogia e pedagogia, para quê? 12. ed. São Paulo: Cortez, 2010.

Didática. 2. ed. São Paulo: Cortez, 2013. 
MARANDINO, Martha. Faz sentido ainda propor a separação entre os termos educação formal, não formal e informal? Ciências \& Educação, v. 23, n. 4, p. 811-816, 2017. Disponível em: <http://www.scielo.br/pdf/ciedu/v23n4/1516-7313-ciedu-23-04-0811.pdf>. Acesso em: 10 jan. 2020.

MARQUES, Joana Brás Varanda; FREITAS, Denise de. Fatores de características da educação não formal: uma revisão da literatura. Educação e Pesquisa, v. 43, n. 4. p. 1087-1110, 2017. Disponível em: <http://www.scielo.br/pdf/ep/v43n4/1517-9702-ep-S15179702201701151678.pdf>. Acesso em: 24 jan. 2020.

MARTINS, Cláudio Souza. O planetário: espaço educativo não formal qualificando professores da segunda fase do Ensino Fundamental para o ensino formal. Goiânia, 2009. Dissertação (Mestrado em Educação) - Universidade Federal de Goiás.

MASSONI, Neusa Terezinha; MOREIRA, Marco Antonio. Pesquisa qualitativa em educação em Ciências: projetos, entrevistas, questionários, teoria fundamentada, redação científica. São Paulo: Editora Livraria da Física, 2016.

OLIVEIRA, M. K. Vygotsky - aprendizado e desenvolvimento: um processo sóciohistórico. 4. ed. São Paulo: Scipione, 2000.

PINA, Onilton Cézar. Contribuições dos espaços não formais para o ensino e aprendizagem de ciências de crianças com Síndrome de Down. Goiânia, 2014. Dissertação (Mestrado em Educação) - Universidade Federal de Goiás.

PORTILHO, Evelise. Como se aprende? estratégias, estilo e metacognição. Rio de Janeiro: Wak Editora, 2009.

VASCONCELLOS, Celso dos Santos. Planejamento: projeto de ensino-aprendizagem e projeto político-pedagógico. 24. ed. São Paulo: Libertad, 2014. 